\title{
Prediction of fly-ash dispersion in the southern Black Sea: A preliminary modelling study
}

\author{
Gökay Karakaş*, Alec James and Alaa Al-Barakati \\ Environmental Technology Centre, UMIST, P.O. Box 88, Manchester M60 1QD, UK
}

\begin{abstract}
The distribution of fly ash that is discharged in the form of slurry from a power plant situated on the southern coast of the Black Sea was simulated with a transport model that used the velocity fields produced by isopycnic modelling. It is shown that a significant amount of ash is deposited in the vicinity of the discharge location. The ash remaining in the water column settles in a manner dependent on the direction and intensity of the local current regime. Generally, summer and spring are found to be seasons when the circulation is weak and the ash dispersion is confined to the shore. The model results are conditional upon obtaining observational data for validation.
\end{abstract}

Keywords: Black Sea, coastal dispersion, fly-ash, isopycnic modelling

\section{Introduction}

In the last few decades of the twentieth century, the ecosystem of the Black Sea was subject to catastrophic changes due to the increasing anthropogenic inputs. While it is nearly in a state of complete isolation from the open ocean dynamics, the Black Sea has become a dumping basin for pollutants of different kinds and origins. Compared with the Mediterranean Sea $\left(1.3 \mathrm{~km}^{2}\right.$ catchment area per $1 \mathrm{~km}^{2}$ of water surface) the Black Sea has a very large catchment area $\left(5.6 \mathrm{~km}^{2}\right.$ per $1 \mathrm{~km}^{2}$ of water surface) [1] and the ecological condition of the basin depends significantly on the processes of its catchment area. A few notable examples include the transport of radionuclides after the Chernobyl accident in 1986, chemical spills following NATO bombing of Yugoslavian refineries during 1999 and heavy metals and cyanide leakage from Romanian mines in 2000.

The nutrients, phosphate and nitrogen, carried by the runoff and the influx of heavily polluted rivers stimulate eutrophication and result in accumulation of hydrogen sulphide in the water column below $150 \mathrm{~m}$ depth. The Danube, itself, brings $60,000 \mathrm{t} / \mathrm{yr}$ of total phosphorus and about $340,000 \mathrm{t} / \mathrm{yr}$ of total inorganic nitrogen to the basin from the northwestern shelf. These amounts are at least 15 times more than the total of those introduced by the rivers on the southern coast $[2,3]$. Eutrophication, for this reason, started in the northwestern shelf and then spread south along the western shelf [4-6]. Parallel to the large increase in the influx of pollutants, the eutrophication of the basin has also augmented sharply during the last decade. Fish stocks have collapsed throughout the basin, invasion by opportunistic species have been observed and the nutrient structure has changed [2,7-10].

However, the deterioration of the ecological system and persistent oppression of marine biota in the Black Sea cannot solely be attributed to the polluted river inflow. The basin

\footnotetext{
* Corresponding author. Current affiliation: Alfred Wegener Institute for Polar and Marine Research, Columbusstrasse, D-27568 Bremerhaven, Germany. E-mail: gkarakas@awi-bremerhaven.de.
}

receives municipal and industrial wastewater effluents and runoff from agricultural and urban areas located along its coast, which consists of oil hydrocarbons, detergents, pesticides, heavy metals and radionuclides. Hence, the contribution of the coast to the eutrophication of the coastal waters of the Black Sea is comparable with that of the large rivers. Mandych and Shaporenko [11], in their quantitative analysis, point out that in a number of areas the ecological state of the coastal waters is almost completely determined by the inflow of pollutants from the coasts.

The coastal waters of the southern town of Zonguldak are one of the heavily polluted areas of recent decades. Uzun and Tigli [12] report that the quality of coastal waters along Zonguldak has deteriorated significantly and fish stocks in the region have declined during recent years due to the increased discharge of industrial wastes that have not had a proper treatment. The coal fired Çatalağzı thermal power plant (ÇATES) is one of the major sources of pollution in the region. Fly ash generated in ÇATES is captured by a series of cyclones and electrostatic precipitators and then discharged directly from the shore into the sea in the form of slurry. Consequently the ÇATES fly ash has become the focus of ecological concerns [13].

The disposal of fly ash into the marine environment has long been a practice in the UK. Large amounts of fly ash from coal fired power plants were dumped $\sim 5 \mathrm{~km}$ off Northumberland coast at depths ranging from 20 to $45 \mathrm{~m}$ for four decades prior to 1993 [14]. A large area of the seabed has been completely covered by fly ash deposits in the dumping region [15] from where elevated metal concentrations are reported in the sediments [16]. Bamber [17] argues that the ash exerted no chemical effect on the biota but was inhibitory to fauna due to its uniform particle size, low permeability and lack of any organic food sources. It is thought that the deposition of fly ash has led to the almost total depletion of the benthos at the dumpsite [14,15]. Kress et al. [18] and Kress et al. [19] studied the effects of fly ash disposal at a deepwater site in the eastern Mediterranean Sea and echo 
the reports of previous authors that there is a severe impoverishment of the benthos in the disposal area.

Nevertheless Crecelius [20], Crecelius [21] and Harvey [22] suggest that ocean disposal of fly ash in sites beyond the continental shelf can be an environmentally viable option. These authors examine the results of solubility tests for metals from ash and also field studies to support their argument. They show that bio-accumulation and toxicity levels of the ash (in the liquid phase, as suspended particulate phase constituents and in the solid phase) in the water column are well below the existing U.S. Environmental Protection Agency (EPA) marine water quality criteria and that effects on primary production are negligible. However, in order to reach this conclusion, these authors assume a limited number of dumping operations over a specified area. Crecelius [20], for instance, assumes the discharge of 7,000,000 $\mathrm{t}$ ash over a $100 \mathrm{~km}^{2}$ area in 20 dumping operations over the year and concludes that the concentration of the soluble metals will not increase with successive dumps. In the specific case of the ÇATES, on the other hand, the fly ash is directly and continuously disposed from the shore into the sea. Therefore, although the number of studies are far from being sufficient to offer a concrete explanation of the interaction of fly ash with plankton, we expect higher metal concentrations and consequently adverse effects on plankton and small nektons in the coastal waters, where biological productivity is usually higher than interior waters.

Egemen and Yurteri [23] applied a variety of toxicity tests, including EPA and ASTM (American Society of Testing and Materials) procedures, to fly ash samples acquired from the ÇATES. They showed that according to the criteria of EPA the ash was not hazardous but $\mathrm{Cd}$ concentrations measured in the extracts exceeded the limits specified in the Turkish Water Pollution Control Regulation of 1988. Rose et al. [24] carried out an ecological assessment study for the coal ash dumped at Deepwater Dumpsite-106, located $240 \mathrm{~km}$ east of Delaware, U.S.A. They point out that the elutriate from the ash is ecologically acceptable for oceanic discharge according to EPA standards, but oil and grease in the elutriate may pose an environmental hazard. This latter finding is in parallel with the significantly elevated levels of oil and grease reported off ÇATES discharge area [12].

There is, evidently, an urgent need for a coherent and successful management of the coastal waters of the Black Sea and its ecosystem in general in order to stop its further deterioration and to provide an environmentally acceptable waste disposal. A better understanding of advective and diffusive processes of pollutants and of the interaction between the specific hydrodynamic processes of the basin and pollutant transport form a crucial part of this management strategy.

The present paper in this context is an attempt to contribute this understanding by making use of numerical models. Having the hydrodynamics of the basin simulated with reasonable success by isopycnic modelling to define its circulation [25], we herein examined the dispersion of the fly ash of ÇATES in the southwestern part of the Black
Sea with a transport model, Environmental Fluid Dynamics Code (EFDC).

\section{Basic features of the model}

EFDC is a three dimensional hydrodynamic and transport model for estuarine and coastal waters. The code solves vertically hydrostatic, free surface, turbulent-averaged equations of motions for a variable density fluid. Dynamically coupled transport equations for turbulent kinetic energy, turbulent length scale, salinity and temperature are also solved. The model is capable of simulating the transport and fate of cohesive and noncohesive suspended sediment. The EFDC uses a stretched or sigma vertical coordinate and cartesian or curvilinear, orthogonal horizontal coordinates. The sigma coordinate system allows a smooth representation of the topography and also the same order of vertical resolution for the shallow and deeper parts of the water body. The transport of cohesive and noncohesive suspended sediment is based on the same high order advection-diffusion scheme used for salinity and temperature. A number of options are included for the specification of settling velocities. Sediment mass conservative deposited bed formulations are included for both cohesive and noncohesive sediment.

The depositional sediment flux $(S)$ is found from:

$$
S= \begin{cases}w_{s} C\left(1-\frac{\tau_{b}}{\tau_{\mathrm{dep}}}\right) & \text { if } \tau_{b}<\tau_{\mathrm{dep}} \\ 0 & \text { otherwise }\end{cases}
$$

where $w_{s}$ is settling velocity of sediment particles, $C$ is sediment concentration, $\tau_{b}$ is the bottom boundary or bed stress and $\tau_{\text {dep }}$ is the critical shear stress for deposition [26]. According to Grant and Madsen [27], $\tau_{\text {dep }}$ for noncohesive sediments can be found from a Shield's parameter ratio:

$$
\begin{aligned}
& \frac{\theta^{\prime}}{\theta_{c}}=1.8 S_{*}^{0.6}, \\
& S_{*}=\frac{d}{4 v}\left(\frac{\rho_{s}-\rho}{\rho} g d\right)^{1 / 2},
\end{aligned}
$$

where $\theta^{\prime}$ is the maximum value of Shields' parameter, $\theta_{c}$ is the critical value for initiation of motion, $S_{*}$ is a dimensionless sediment parameter, $d$ is the sediment diameter, $v$ is the kinematic viscosity, $\rho_{s}$ is the sediment density $\rho$ is water density and $g$ is the acceleration of gravity.

The sediment resuspension rate $(E)$ in the model is determined from

$$
E= \begin{cases}E_{r}\left(\frac{\tau_{b}-\tau_{r}}{\tau_{n}}\right)^{\theta_{c}} & \text { if } \tau_{b}>\tau_{r}, \\ 0 & \text { otherwise. }\end{cases}
$$

In the above equation $E_{r}$ is the reference resuspension rate, $\tau_{r}$ is the boundary stress above which resuspension takes place and $\tau_{n}$ is the normalising stress. The parameter $E_{r}$ is only used in cohesive sediment transport calculations, and for noncohesive sediment transport $\tau_{r}$ and $\tau_{n}$ are both equal 


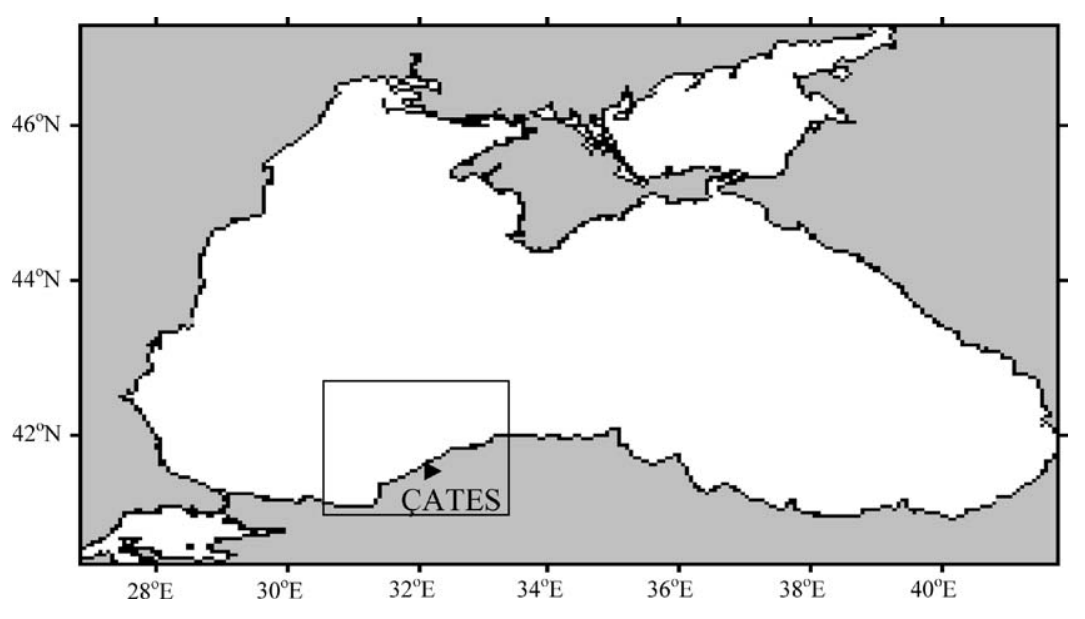

Figure 1. Model region for fly-ash dispersion.

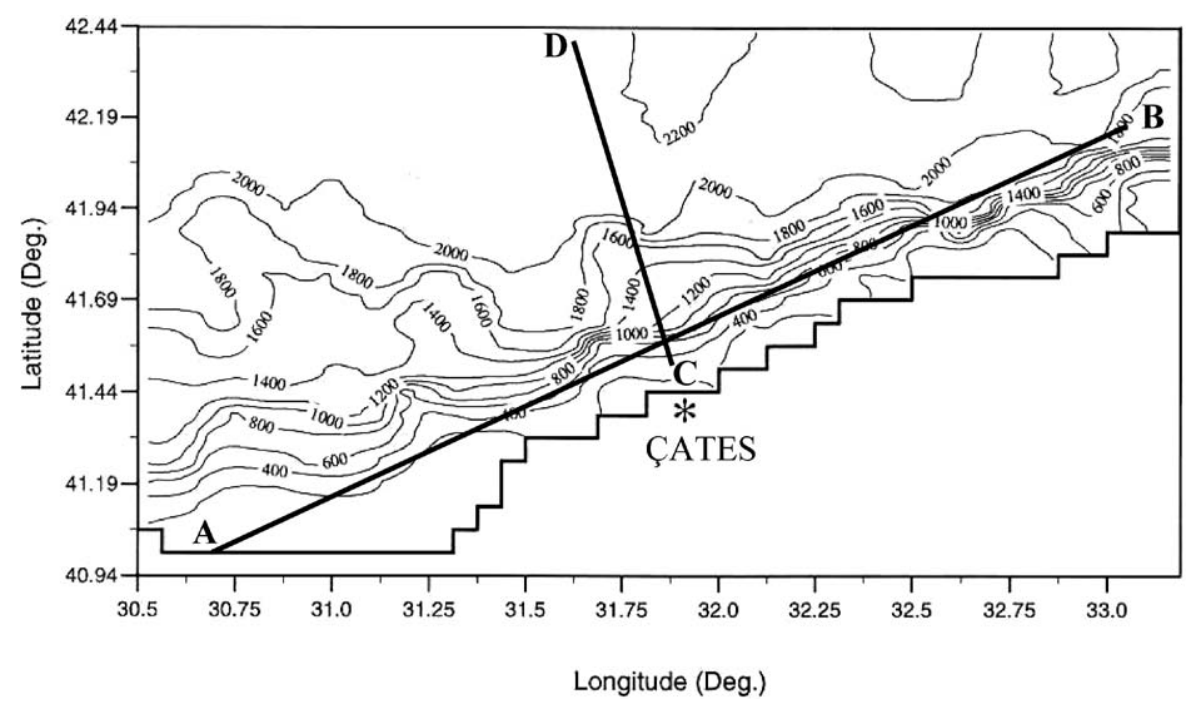

Figure 2. Topography of the model domain and location of ÇATES.

Table 1

Layer thicknesses used in the model.

\begin{tabular}{cc}
\hline Layer No. & Dimensionless layer thickness \\
\hline 1 & 0.025 \\
2 & 0.025 \\
3 & 0.05 \\
4 & 0.1 \\
5 & 0.1 \\
6 & 0.1 \\
7 & 0.1 \\
8 & 0.1 \\
9 & 0.2 \\
10 & 0.2
\end{tabular}

to the critical stress for incipient sediment motion, which is determined from the critical Shields' parameter.

\section{Model geometry and initialisation with transport-only-mode}

The model domain to simulate the dispersion of fly ash discharged from ÇATES is illustrated on the Black Sea map in figure 1. In the following figure (figure 2) we show the location of the power plant and the model bottom topography. The size of the area was chosen in accordance with the similar previous work, mainly on dredged material disposal into marine environment (see Clarke et al. [28], Fry and Butman [29], de Kok [30], Churchill and Aikman [31]). The boundaries of the domain lie between longitudes $30.5^{\circ} \mathrm{E}$ to $33.1875^{\circ} \mathrm{E}$ and latitudes $40.9375^{\circ} \mathrm{N}$ to $42.4375^{\circ} \mathrm{N}$. A grid resolution of $0.0625^{\circ}$ latitude $\times 0.0625^{\circ}$ longitude was employed for the horizontal plane. In the vertical, 10 layers were chosen with dimensionless thicknesses summing up to 1 as shown in table 1 . Higher resolution is assigned to the surface layers.

Although EFDC has been widely applied to a variety of estuaries and coastal environments, steep topography of our domain is a drawback in using such a sigma coordinate model, which usually induces unrealistic velocity fields as a result of strong pressure gradients. Hence, having relatively successful results from previously simulated circulation of the Black Sea by an isopycnic coordinate model [25], the EFDC model was run in transport-only-mode to exam- 

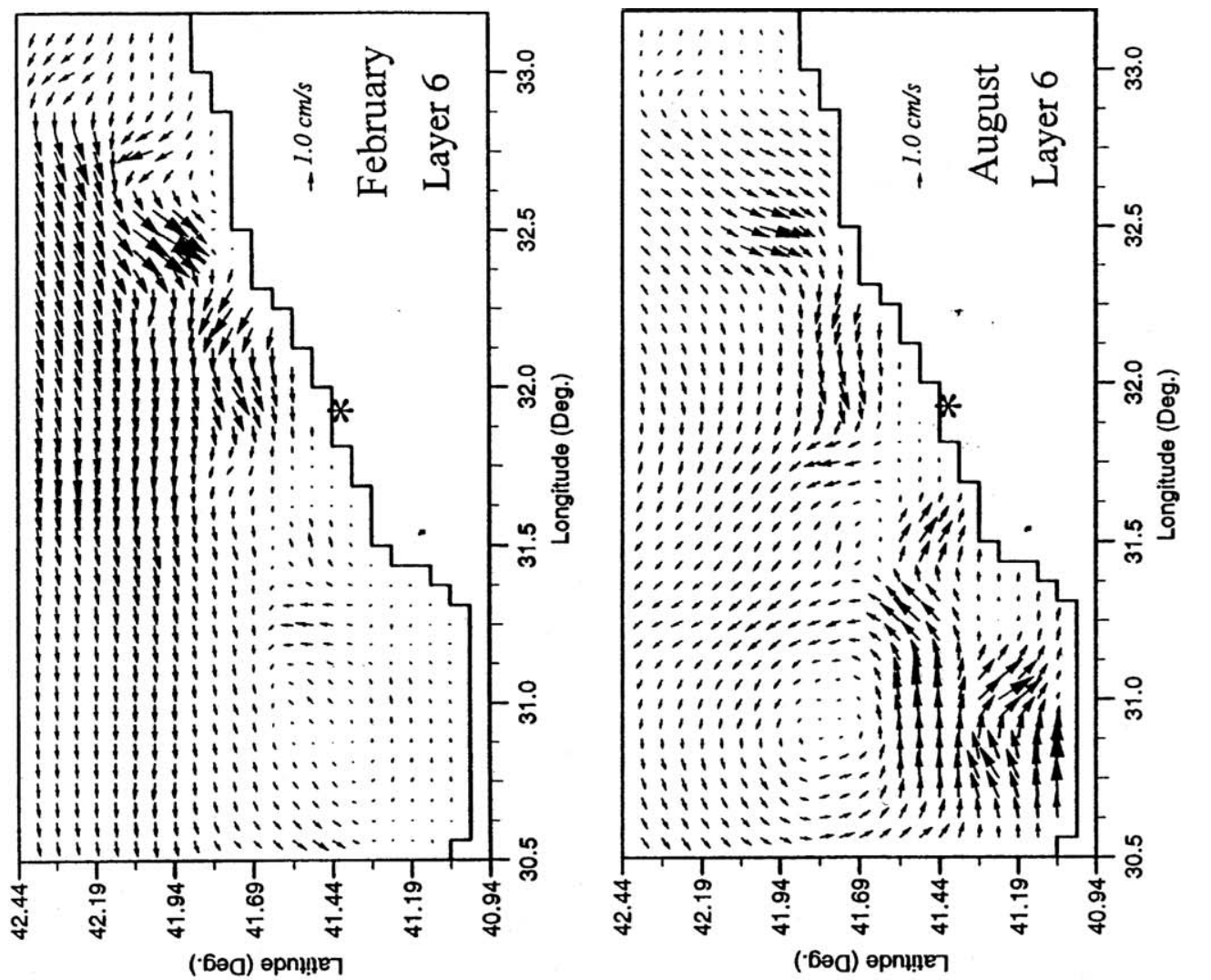

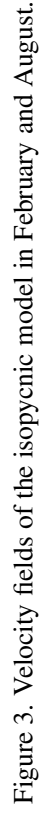
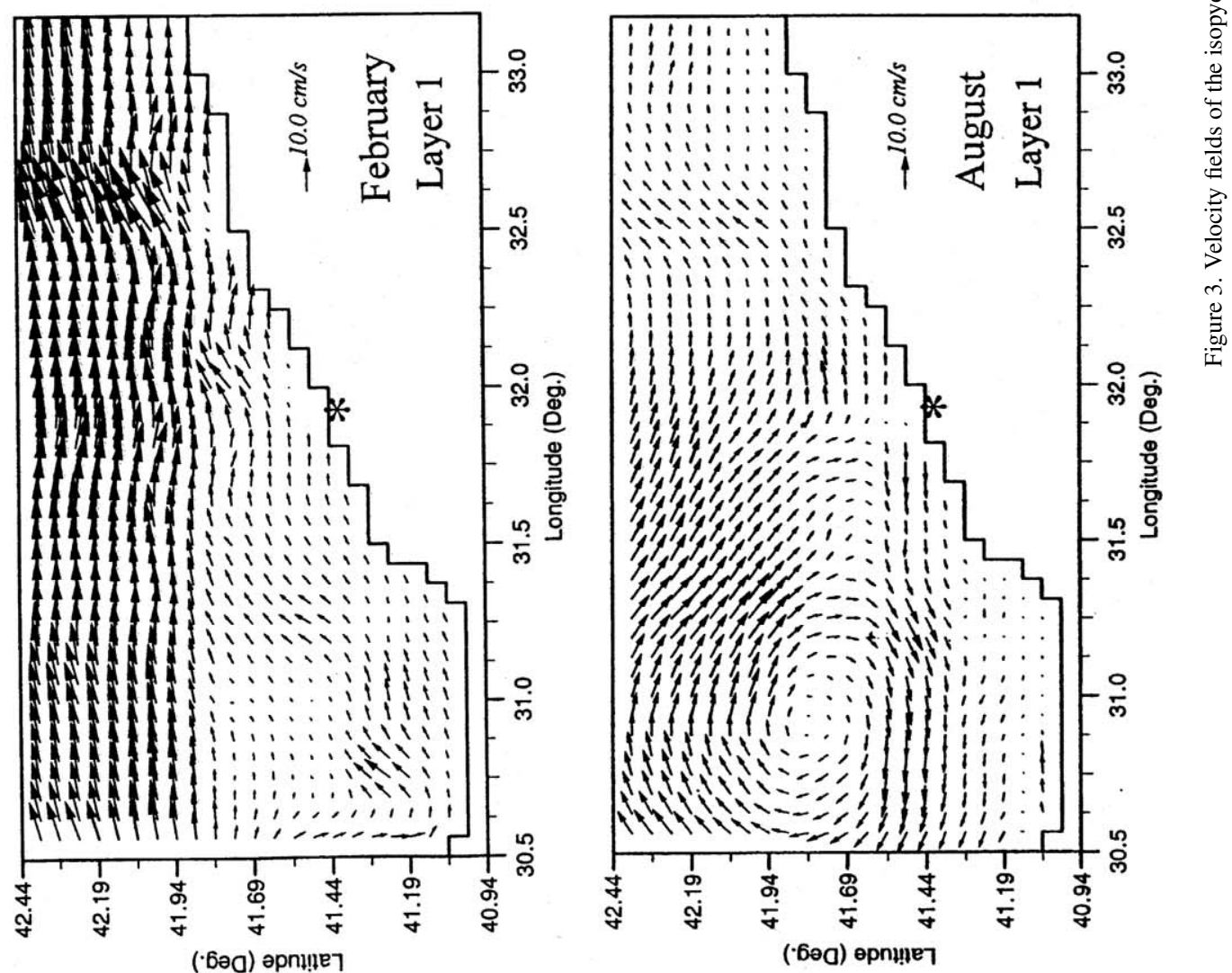


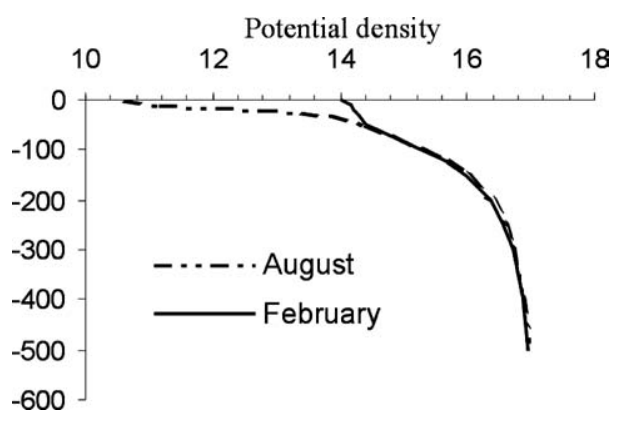

Figure 4. February and August density profiles used in the model.

ine fly-ash dispersion by specifying advective and diffusive transport as separate input files. We, therefore, interpolated the monthly averaged velocity fields to the model grid from the isopynic model of the basin. Figure 3 shows the velocity fields in February and August, taking these to be representative of winter and summer patterns respectively, for layers 1 (surface) and 6 (below the pycnocline). The density profiles, on the other hand, were calculated from Altman's data set [32], which consists of CTD and Nansen bottle measurements at 22 vertical levels made over 70 years. The resultant density profiles in February and August are illustrated in figure 4. Horizontal momentum and mass diffusivity was taken as $500 \mathrm{~m}^{2} / \mathrm{s}$ as calculated by Eremeev and Kushnir [33] for the Black Sea. Molecular diffusivity and molecular kinematic viscosity, on the other hand, were chosen as the typical values of $1 \times 10^{-9} \mathrm{~m}^{2} / \mathrm{s}$ and $1.4 \times 10^{-6} \mathrm{~m}^{2} / \mathrm{s}$, respectively.

\section{Fly ash characteristics}

It is reported that daily $2000 \mathrm{t}$ fly ash is discharged from ÇATES in the form of slurry after being mixed with $10 \mathrm{~m}^{3}$ seawater [13]. We introduced this amount as a constant volumetric source to the surface layer of the model grid corresponding to the geographical location of the ÇATES. Because $14 \%$ of fly ash is reported as clay size [24], this portion of the ash was considered as cohesive and the rest being noncohesive. The density of the ash was taken as $2.1 \mathrm{~g} / \mathrm{cm}^{3}$ [13], the specific gravity is typically chosen as 2.0 [34] and the settling velocity was taken as $17 \mathrm{~cm} / \mathrm{s}[18,24]$.

For the cohesive portion of the fly ash, the boundary stress below which deposition takes place, the boundary stress above which resuspension takes place and the normalising stress, which are to be used in the resuspension and deposition formulas in section 2 above, were taken as the typical values of estuarine cohesive sediment [26]. For noncohesive fly ash, on the other hand, the boundary stress for deposition was calculated from the equations (1) and (2) with a typical fly ash diameter of $0.021 \times 10^{-3} \mathrm{~m} \mathrm{[35]} \mathrm{and} \mathrm{the}$ corresponding critical Shields' parameter of approximately 0.8 . The critical shear stress for resuspension $\left(\tau_{c}\right)$ is found from the relation [36]:

$$
\theta_{c}=\frac{\tau_{c}}{\left(\rho_{s}-\rho\right) g d}
$$

\section{Results and discussion}

The model was run for 10 days for every month with corresponding density and velocity fields. Herein we report the distribution of fly ash in February and August. Horizontal distributions are shown at $5 \mathrm{~m}$ depth, while vertically the distributions are illustrated along 2 sections, one of them (section $\mathrm{A}-\mathrm{B}$ ) parallel to the coastline and one (section $\mathrm{C}-\mathrm{D}$ ) perpendicular off the coast towards the open sea as shown in figure 2. Because most of the ash was deposited over the discharge location, the concentration values in the figures are given in logarithmic form to give a more clear representation of the variation of fly ash distribution over the whole model domain.

In February, horizontal distribution pattern show that most of the fly ash is dispersed towards northeast with some being directed to west (see figure 5). However, vertical distribution along the coastline (section $\mathrm{A}-\mathrm{B}$ ) demonstrates that under the influence of subsurface westerly and southwesterly currents in the western part of the discharge point, the portion of ash in this part is carried away towards southwest parallel to the coast, while those in the eastern side of the discharge location settle down after driven by surface northeasterly currents (see figure 6). Moreover, vertical section C-D illustrates that as soon as they are discharged large quantities of ash are deposited in the vicinity of the discharge location.

In August, surface currents in the discharge area separate into two channel flowing in opposite direction to one another. One of these currents heads to the northeast and the other is to the west under the influence of an anti-cyclonic eddy (see figure 3 ). The discharged ash, for this reason, is more locally confined in this month but still under the influence of relatively weak current regime and therefore is dispersed along two separate flows (figures 7 and 8).

The simulation results show that while a great portion of fly ash settles just after being discharged, the dispersion of the ash remaining in the water column is significantly dependent upon the water circulation in the locality of the discharge point. Consequently, the distribution pattern exhibits seasonal variation. Whilst it is carried away by relatively strong surface currents in winter, meandering Rim Current towards the coast where the ÇATES is located traps the ash in that vicinity during summer. As this flow approaches to the shore, it separates into two currents. One of them is directed to the west and joins the anti-cyclonic eddy near Cape Baba at about $31^{\circ} \mathrm{E} 41.8^{\circ} \mathrm{N}$ and the other component heads towards east with the cyclonic Rim. Since the current velocities are very low off the ÇATES coast during spring and summer months, the larger amount of ash is deposited in the discharge location.

It is normal to expect that the fraction of ash joining the anti-cyclonic eddy settle faster due to the convergence. This might be favourable since the time that ash remains in the water column is shorter. On the other hand, higher concentrations of ash and hence its dissolved components are anticipated in the convergence zones. Therefore, whether this 


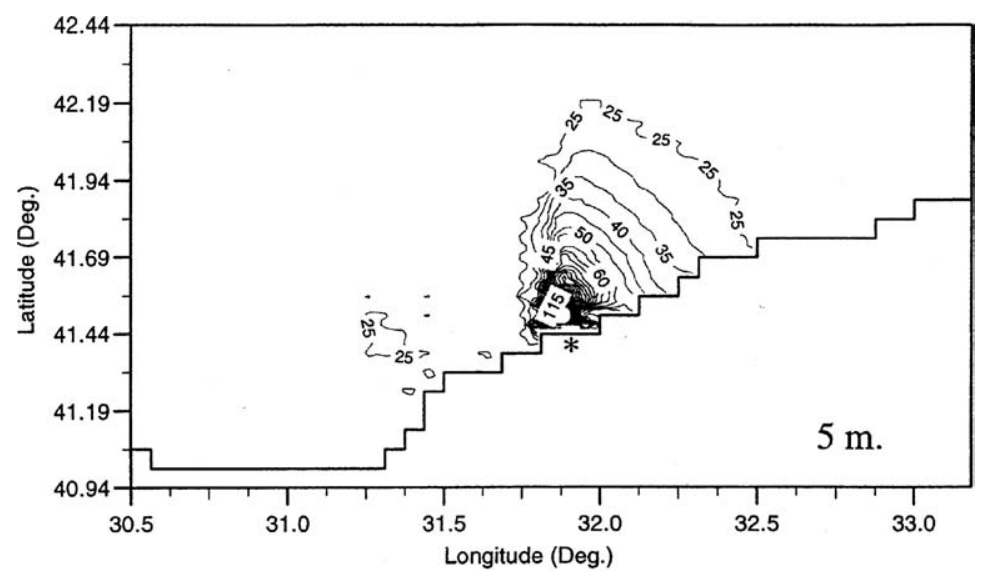

Figure 5. Horizontal fly-ash distribution $\left(-1000 / \log\right.$ conc. $\left.\left(\mathrm{mg} \mathrm{l}^{-1}\right)\right)$ in February.
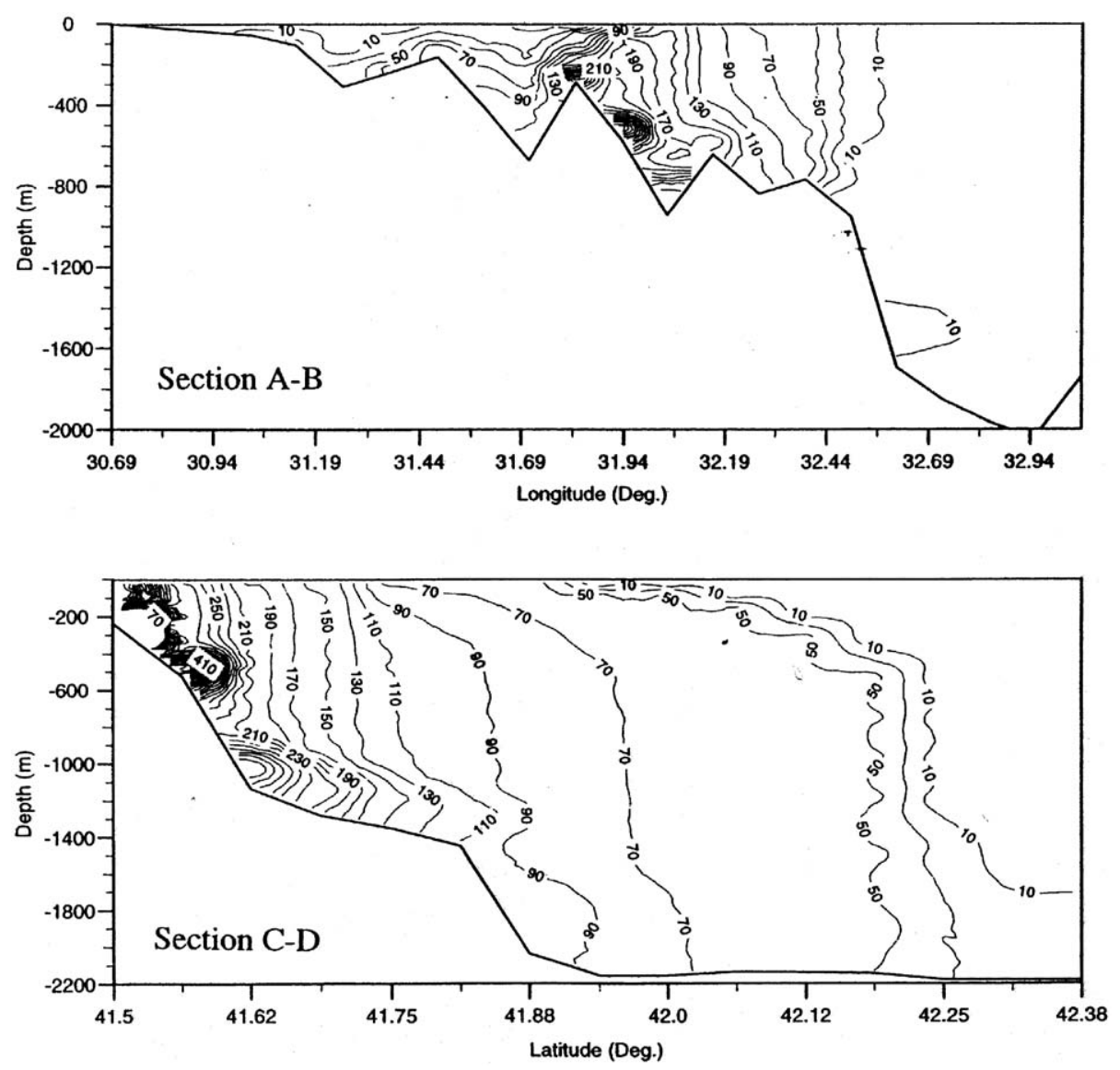

Figure 6. Vertical fly-ash distribution $\left(-1000 / \log\right.$ conc. $\left.\left(\mathrm{mg}^{-1}\right)\right)$ along cross sections A-B and C-D in February.

is promising or not in terms of the health of marine species depends on the factors like the relation between the ash concentration and uptake kinetics of its dissolved components by planktons and nektons, the time, position and depth extend of biological productivity and so on.

The results show no noticeable effect of pycnocline on fly ash dispersion. This is consistent with the observations had during the monitoring of the disposal of fly ash in an eastern Mediterranean dumpsite [18]. Although several authors $[29,37]$ report that some portion of dumped waste material is retained at the seasonal pycnocline when the density of the waste cloud reaches that of the surrounding water, this is unlikely with fly ash. The reason is simply that ash has an approximate density of $2.1 \mathrm{~g} / \mathrm{cm}^{3}$, which is much greater than the Black Sea water density $\left(\sim 1.016 \mathrm{~g} / \mathrm{cm}^{3}\right)$. Once the fly ash is deposited on the seabed it might be resuspended, this is estimated from the sum of the tidal velocities, net bottom currents and wave-induced oscillatory currents. However bedload movement of ash is not expected since the minimum current velocity estimated to initiate the motion of ash 


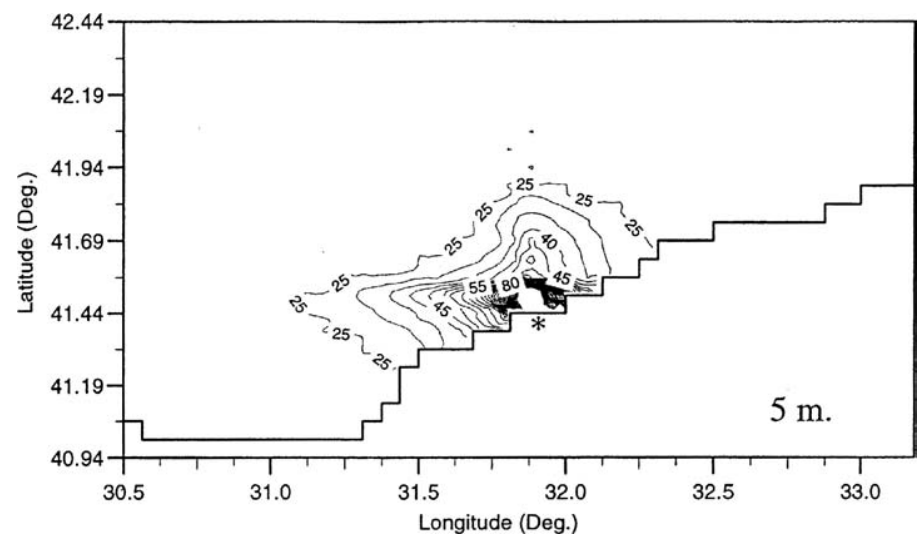

Figure 7. Horizontal fly-ash distribution $\left(-1000 / \log\right.$ conc. $\left.\left(\mathrm{mg}^{-1}\right)\right)$ in August.
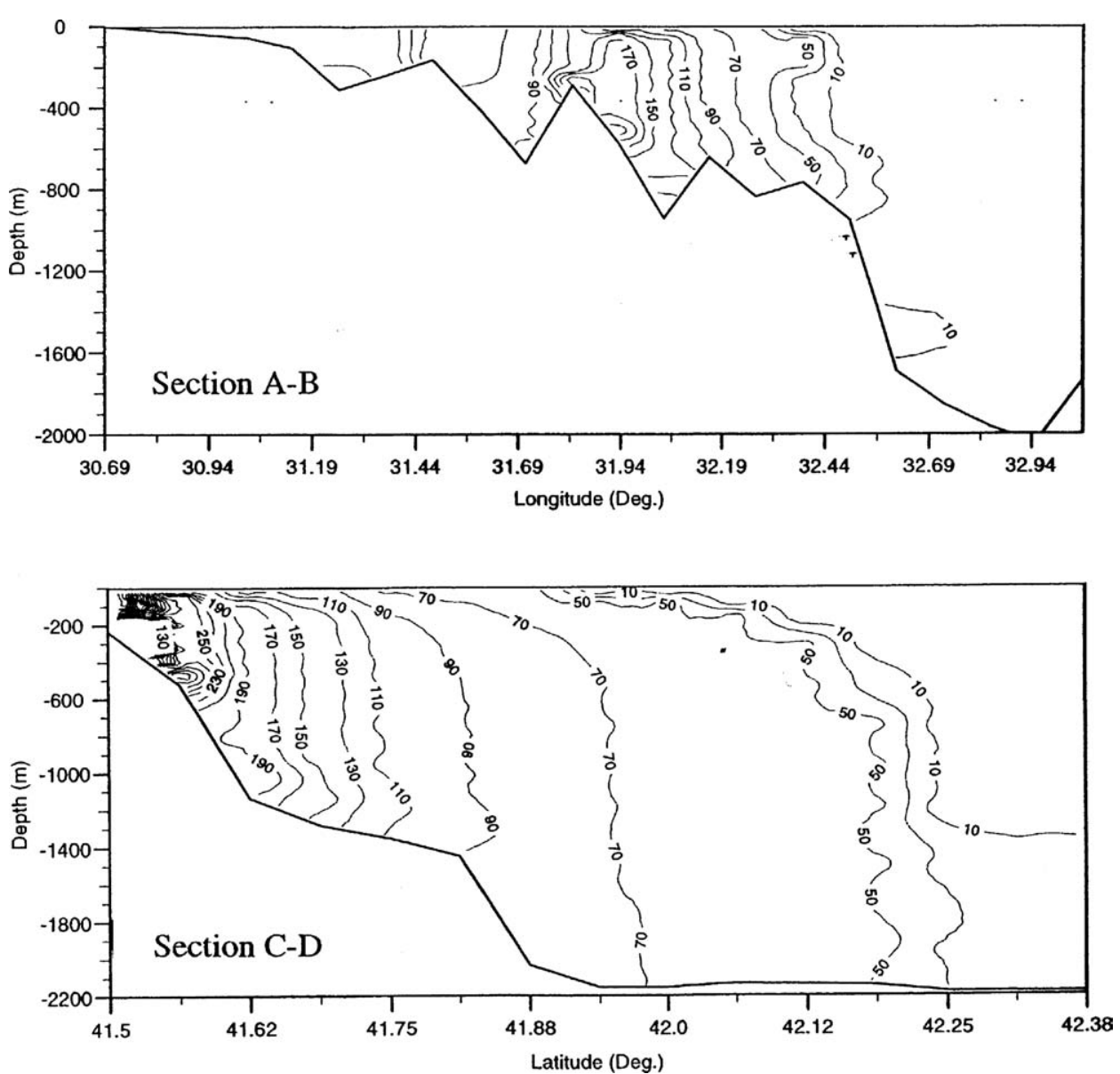

Figure 8. Vertical fly-ash distribution $\left(-1000 / \log\right.$ conc. $\left.\left(\mathrm{mg}^{-1}\right)\right)$ along cross sections A-B and C-D in August.

is $40 \mathrm{~cm} / \mathrm{s}$ [15], which is much faster than the bottom velocities off the ÇATES.

This modelling study presents some limitations for no observational data is available to compare the results. Although the density of the fly-ash that is used in the model is the value measured by ÇATES, the clay size and settling velocity are the values of the same type of ash from elsewhere. It would be preferable to conduct size distribution analysis and settling tests of the ÇATES ash.

The validation of model results require some extensive field data in the region. Deployment of a number of sediment traps off shore and nearby discharge location of the fly-ash would provide such modelling studies with enormous data for comparison and improvement of the numerical work. In addition more reliable flow fields can be obtained with the help of current meter measurements. Finally near shore wave dynamics can have a considerable effect in the dispersion of fly-ash, which is not included in the present work. Integrating a wave component to the model may give relatively different dispersion fields of fly-ash in short-time scales. 


\section{Conclusions and recommendations}

The present work uses a three-dimensional transport model to simulate the dispersion of fly ash from the ÇATES coal-fired power plant, which is one of the major industrial sources of pollution along the southern coast of the Black Sea. We believe that the modelling studies like the one presented here are essential in determining the spatial extent of expected damage to the marine life, as a component of environmental monitoring activities, as well as offering a basis for further prediction of secondary transport and bioaccumulation processes.

It was illustrated that great portion of ash deposits in the vicinity of the discharge location. The ash remaining in the water column settles depending on the direction and intensity of the current regime. Generally, summer is revealed as the season when the circulation is weak and ash dispersion is confined along the coast.

The results presented in this paper are conditional on obtaining observational data for validation. It is also worth noting that the present study neglects the near shore dispersion and the local action of waves due to the coarse resolution of the model grid and lack of wave data in the vicinity of the discharge location. Since the ash is discharged in the form of a slurry via a short pipeline directly onto the foreshore, it is expected that a more detailed dispersion pattern of ash can only be simulated by introducing fine resolution wave, atmospheric and current meter data. Extensive field measurements are also a must for the validation of models like the present study, which can lead to further modelling work and studies on the possible influence on retardation of biological growth, interaction of ash with zooplankton and small nekton. Its long-term cumulative effects, the position of affected organisms in the ecological food web and the toxicity of bioaccumulated constituents to human consumers of seafood are the areas requiring further investigation.

Lastly, the authorities should be urged to find an alternative disposal strategy for the fly ash. The already-critical condition of the Black Sea is no longer in a position to tolerate such massive pollutant burdens.

\section{Acknowledgements}

We would like to thank Dr John Hamrick for his advice during the setting up of the EFDC code. Thanks also go to Dr Temel Oguz of Erdemli Institute of Marine Sciences for providing Altman's dataset.

\section{References}

[1] A.V. Drozdov and A.F. Mandych, Black Sea environment, GeJournal 27(2) (1992) 139-140.

[2] L.D. Mee, The Black Sea in crises: the need for concerted international action, Ambio 24 (1992) 278-286.

[3] E. Ozsoy, M.A. Latif, S. Tugrul and U. Unluata, Exchanges with the mediterranean, fluxes and the boundary mixing processes in the Black
Sea, presented at the Black Sea Symposium, International Commission for the Science and Exploration of the Mediterranean Sea, Trieste, 12-17 October (1992).

[4] E.I. Musayeva, Mesoplankton near the Bulgarian Coast, Oceanology 25 (1985) 647-652.

[5] D. Tolmazin, Changing coastal oceanography of the Black Sea, I. Northwestern Shelf, Prog. Oceanogr. 15 (1985) 217-276.

[6] A.S. Bologa, Planktonic primary productivity of the Black Sea: A review, Thalassia Jugosl. 22 (1986) 1-22.

[7] D.G. Aubrey, Z. Belberov, A. Bologa, V. Eremeev and U. Unluata, A coalition to diagnose the patient: CoMSBlack and the Black Sea, Mar. Technol. 2 (1992) 5-8.

[8] S. Tugrul, O. Basturk, C. Saydam and A. Yilmaz, Changes in the hydrochemistry of the Black Sea inferred from water density profiles, Nature 359 (1992) 137-139.

[9] A.E. Kideys, Recent changes in the Black Sea ecosystem: the reason for the sharp decline in Turkish fisheries, J. Mar. Syst. 5 (1994) 171181.

[10] S.V. Berdnikov, V.V. Selyutin, V.V. Vasilchenko and J.F. Caddy, Trophodynamic model of the Black and Azov Sea pelagic ecosystem: consequences of the comb jelly, Minemiopsis leydei invasion, Fish. Res. 42 (1999) 261-289.

[11] A.F. Mandych and S.I. Shaporenko, Influence of the economic activities on coasts upon the coastal waters of the Black Sea, GeoJournal 27 (1992) 195-206.

[12] N. Uzun and K. Tigli, Zonguldak'da Çevre ve Deniz Kirliliği, Zonguldak İli Çevre Durum Raporu, Zonguldak Çevre İl Müdürlügüu, Ankara (1993).

[13] H. Sari, ÇATES-B Termik Santrali Hakkında Özet Bilgiler, ÇATES-B Termik Santrali Eğitim Servisi, TEAŞ, Ankara (1994).

[14] S. HerrandoPerez and C.L.J. Frid, The cessation of long-term fly-ash dumping: Effects on macrobenthos and sediments, Mar. Pollut. Bull. 36(10) (1998) 780-790.

[15] M.G. Norton, Colliery-waste and fly-ash dumping off the northeastern coast of England, in: Wastes in the Ocean 4: Energy Wastes in the Ocean, eds. I.W. Duedall, D.R. Kester, P.K. Park and B.H. Ketchum (Wiley, New York, 1985) pp. 423-448.

[16] R.A. Eagle, M.G. Norton, R.S. Nunny and M.S. Rolfe, The field assessment of effects of dumping wastes at sea 2: Methods. Fisheries Research Technical Report No. 47, Ministry of Agriculture, Food and Fisheries, Lowestoft, UK (1978).

[17] R.N. Bamber, The properties of fly ash as a marine sediment, Mar. Pollut. Bull. 11 (1980) 323-326.

[18] N. Kress, A. Golik, B. Galil and M.D. Krom, Monitoring the disposal of coal fly ash at a deep water site in the Eastern Mediterranean Sea, Mar. Pollut. Bull. 26(8) (1993) 447-456.

[19] N. Kress, H. Hornung and B. Herut, Concentrations of $\mathrm{Hg}, \mathrm{Cd}, \mathrm{Cu}$, $\mathrm{Zn}, \mathrm{Fe}$ and $\mathrm{Mn}$ in deep sea benthic fauna from the southeastern Mediterranean Sea: A comparison study between fauna collected at a pristine area and at two waste disposal sites, Mar. Pollut. Bull. 36(11) (1998) 911-921.

[20] E.A. Crecelius, The solubility of coal fly ash and marine aerosols in sea water, Mar. Chem. 8 (1980) 245-250.

[21] E.A. Crecelius, Fly-ash disposal in the ocean: an alternative worth considering, in: Wastes in the Ocean 4: Energy Wastes in the Ocean, eds. I.W. Duedall, D.R. Kester, P.K. Park and B.H. Ketchum (Wiley, New York, 1985) pp. 379-388.

[22] S.E. Harvey, Disposal of coal wastes in the marine environment, in: Oceanic Processes in Marine Pollution 3: Marine Waste Management Science and Policy, eds. M.A. Champ and P.K. Park (Robert Krieger Publishing, FL, 1989) pp. 85-99.

[23] E. Egemen and C. Yurteri, Regulatory leaching tests for fly ash: A case study, Waste Manag. Res. 14 (1996) 43-50.

[24] C.D. Rose, T.J. Ward and V.E. de Pass, Ecological assessment for coal ash dumped at deepwater dumpsite-106, in: Wastes in the Ocean 4: Energy Wastes in the Ocean, eds. I.W. Duedall, D.R. Kester, P.K. Park and B.H. Ketchum (Wiley, New York, 1985) pp. 246-268. 
[25] G. Karakas, A. James and A. Al-Barakati, Modelling subsurface dynamics in the Black Sea, Oceanol. Acta 25 (2002) 101-116.

[26] J.M. Hamrick, Users manual for the environmental fluid dynamics computer code. The College of William and Mary, Virginia Institute of Marine Science, Special Report 328, Virginia (1996).

[27] W.D. Grant and O.S. Madsen, Movable bed roughness in unsteady oscillatory flow, J. Geohys. Res. 87 (1982) 469-481.

[28] T.L. Clarke, D.J.P. Swift and R.A. Young, A numerical model of fine sediment transport on the continental shelf, Environ. Geol. 4 (1982) 117-129.

[29] V.A. Fry and B. Butman, Estimates of the seafloor area impacted by sewage sludge dumped at the 106-mile site in the Mid-Atlantic Bight, Mar. Environ. Res. 31 (1991) 145-160.

[30] J. de Kok, A three-dimensional finite difference model for computation of near- and far-field transport of suspended matter near a river mouth, Cont. Shelf Res. 12 (1992) 625-642.

[31] J.H. Churchill and F. Aikman, The impact of fine particles discharged at the 106-mile municipal sewage sludge dump site, J. Mar. Env. Eng.
2 (1996) 181-202.

[32] E.N. Altman, I.F. Gertman and Z.A. Golubeva, Climatological Fields of Salinity and Temperature in the Black Sea (Sevastopol Branch, State Oceanography Institute, Sevastopol, Ukraine, 1987).

[33] V.N. Eremeev and V.M. Kushnir, The layered structure of currents and vertical exchange in the Black Sea, Oceanology 36 (1996) 9-15.

[34] N.S. Pandian, C. Rajasekhar and A. Sridharan, Studies of the specific gravity of some Indian coal ashes, Journal of Testing \& Evaluation 26 (1998) 177-186.

[35] O. Hjelmar, Marine disposal of fly ash from coal fired power plants, Water Sci. Technol. 15 (1983) 109-131.

[36] K.R. Dyer, Coastal and Estuarine Sediment Dynamics (Wiley, London, 1986).

[37] B.H. Johnson, User's guide for models of dredged material disposal in open water, Technical Report D-90-5, Department of the Army, Waterways Experiment Station, Mississippi (1990). 